NASATM- $Z /-\quad 207529$

$A=1, \ldots$

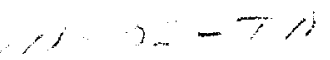

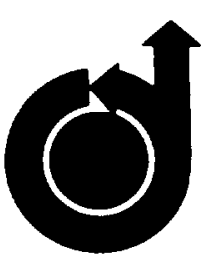

AIAA 78-1476R

Alleviation of Spin-Entry Tendencies through

Localization of Wing-Flow Separation

T. W. Feistel, S. B. Anderson, R. A. Kroeger

Aeprinted Irom

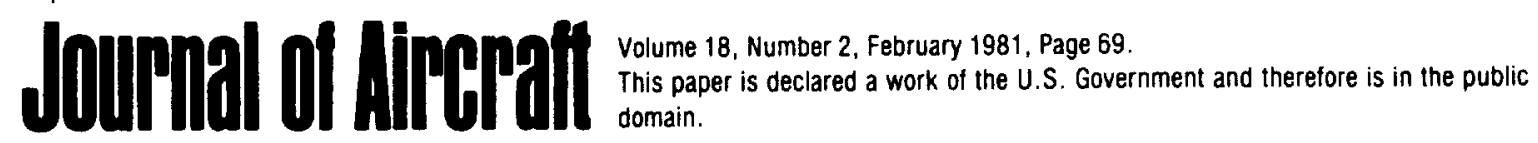




\title{
Alleviation of Spin-Entry Tendencies through Localization of Wing-Flow Separation
}

\author{
T. W. Feistel* and S. B. Anderson $\dagger$ \\ NASA Ames Research Center, Moffett Field, Calif. \\ and \\ R. A. Kroeger $\ddagger$ \\ ARO, Inc., Tullahoma, Tenn.
}

\begin{abstract}
Studies have been made on several wing leading-edge modifications applicable at present to single-engine light aircraft, which produce stabilizing vortices at stall and beyond. These vortices have the effect of fixing the stall pattern of the wing such that the various portions of the wing upper surface stall nearly symmetrically. The lift coefficient produced is maintained at a high level to angles of altack significantly above the stall angle of the unmodified wing, and the divergence in roll usually is reduced to a controllable level. It is hypothesized that these characteristics will help prevent inadvertent spin entry after a stall. Results are presented from recent largescale wind-tunnei tests of a typical light aircraft, both with and without the modificalions. The data indicate that the static stall and poststall characteristics of this aircraft, in a typical landing-approach condition, are noticeably improved when a suitable leading-edge modification is employed; and also that no appreciable aerodynamic penalties are evident in the normal flight envelope.
\end{abstract}

\section{Introduction}

TALLS and spins have continued to be a major cause of fatal and nonfatal accidents involving general aviation aircraft. As discussed in a historical overview of stall/spin characteristics, ${ }^{1}$ the aerodynamic factors that affect stall/spin behavior have been studied for many years and are well known; however, the incorporation of the proper combination of these factors to provide stall/spin avoidance in current general aviation aircraft has proved to be a difficult design challenge.

A key part of providing acceptable stall/spin behavior involves the wing aerodynamics. Lateral instabilities and the loss of lateral control, common to most aircraft when in a stall, are due in large part to a rapid asymmetrical spread of flow separation on the outer portions of the wings. Many methods to control wing-flow separation have been examined. These include aerodynamic twist or geometric washout, wing slots or slats, change in airfoil section, variable thickness ratio, and the use of leading-edge stall strips. Although some of these methods have been somewhat successful in improving stall/spin resistance, either the increased complexity of the wing design and/or loss of performance have acted as deterrents to widespread acceptance by the general aviation industry.

Recently, an improvement in poststall aerodynamic flow control has been made in a research program conducted jointly at Ames Research Center and at the University of Michigan. Basically, as illustrated schematically in Fig. 1, the concept involves the forced shedding of vortices at stall at the midsemispan leading edge. This can serve to preserve the lift, both inboard and outboard, to very large angles of attack.

Recent radio-controlled model tests and full-scale flight tests of a similar flow-control concept performed at Langley Research Center are reported in Ref. 2 . These tests seem to

Presented as Paper 78-1476 at the AIAA Aircraft Systems and Technology Conference, Los Angeles, Calif., Aug. 21-23, 1978; submitted Jan. 19, 1979; revision received May 23, 1980. This paper is declared a work of the U.S. Government and therefore is in the public domain.

-Aerospace Engineer. Member AIAA.

$\dagger$ Research Assistant for Interagency Programs. Associate Fellow AIAA.

‡Program Manager. Member AlAA. support the effectiveness of the concept in preventing inadvertent spin entry, as well as facilitating spin recovery. Further research along these lines is being pursued at Langley Research Center and elsewhere (cf., Refs. 3 and 4).

\section{History of Development}

A preliminary three-dimensional analysis that used a nonlinear-lifting-line approach with a simulated stalled wing section ${ }^{5}$ suggested that strong vorticity would be shed at the edges of the unattached section. A wind-tunnel model was fabricated with partial span slats added along the entire leading edge except for a small length near the midsemispan. This difference in leading-edge configuration was intended to produce a strong streamwise vorticity around the unprotected section at stall and thus, due to a decrease in the local induced angle of attack, keep the other areas attached to high angles of attack (i.e., causing them to behave similarly to low-aspectratio surfaces). By varying the spanwise position and width of the unslatted section, a poststall lift curve shape could then be produced which varied from practically flat on top to doublepeaked, depending on the spanwise position of the gap in the leading-edge slats

This midsemispan flow control technique was developed in experiments in the University of Michigan $5 \times 7 \mathrm{ft}$ Wind Tunnel and in the NASA Ames $7 \times 10 \mathrm{ft}$ Wind Tunnel.

A second series of tests was performed in the NASA Ames $7 \times 10 \mathrm{ft}$ Wind Tunnel using a half-span model; the results are reported in Ref. 6 . In these studies the slats were replaced by leading-edge gloves which added camber and a larger radius to the airfoil leading edge. The results showed similar flow control capabilities, but the effect was not quite as dramatic on the poststall lift curve shape as the slats. However, the gloves were capable of producing a flat-top lift curve without showing perceptible drag penalty with respect to the clean wing. In addition, they were simple enough to constitute an acceptable type of add-on to general aviation aircraft.

Subsequent wind-tunnel studies of an isolated full-span wing in the NASA Ames $7 \times 10 \mathrm{ft}$ Wind Tunnel showed, among other things, that sideslip did not significantly alter the effectiveness of this flow control concept. The unyawed data from this test (Fig. 2) illustrate the variety of lift curve shapes obtainable with different leading-edge configurations. 


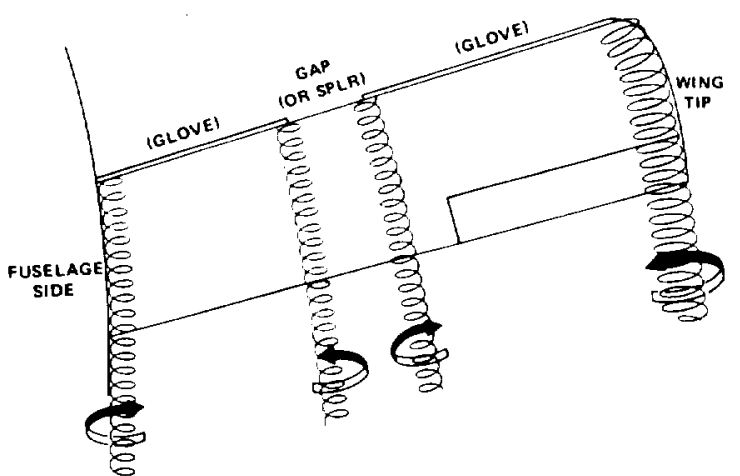

Fig. 1 Schematic sketch of flow control concept.
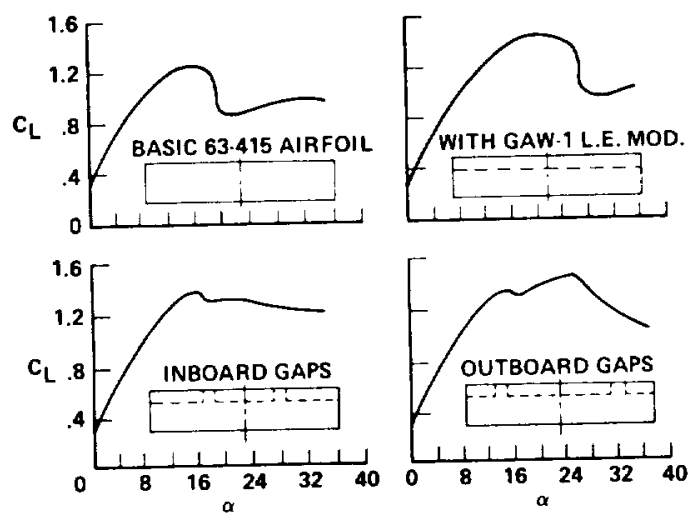

Fig. 2 Lift-curve shapes obtainable with different leading-edge configurations - from test of isolated wing in $7 \times 10 \mathrm{ft}$ wind tunnel.

\section{Full-Scale Wind-Tunnel Tests}

The flow control method was tested on a typical light airplane in the NASA Ames $40 \times 80 \mathrm{ft}$ Wind Tunnel, with and without engine power and with various control surface deflections. This paper presents and discusses some results of these recent studies. The airplane was a Beechcraft Musketeer, Model 23A Fig. 3. The aircraft/wind-tunnel model in the tunnel is shown in Fig. 3.

The aircraft wing was modified by attaching a removable fiberglass leading-edge glove which was capable of being installed in segments. The design of the glove was similar to that used in the earlier $7 \times 10 \mathrm{ft}$ wind-tunnel tests, that is, a matching of the nose of a GAW-1 airfoil to the leading edge of the wing such that the upper surface of the two airfoils approximately coincide over $20-30 \%$ of the chord (a sketch is shown in the lower part of Fig. 4). This design results in a larger leading-edge radius as well as greater camber at the nose; the lower surface was faired flat so that it blended with the bottom of the wing at about $30 \%$ chord. This simple modification served to delay leading-edge separation on the protected span to significantly higher angles of attack.

The leading-edge glove segments were designed so they could be removed and rearranged to produce an unprotected gap, varying from $1 / 16$ to $1 / 2$ of the exposed semispan in width, at various spanwise positions on each of the wings. A sketch of the layout and nomenclature is shown in Fig. 4. Figure 5 is a close-up photograph of a typical modification. The location and width of the unprotected gap were varied systematically during the exploratory part of the tests.

It was found undesirable to test the model for prolonged periods with the horizontal tail on because of severe buffeting in the poststall region. Hence, most of the testing was done with the horizontal tail removed. All of the data in this paper are shown with the tail off to isolate the wing-body effects of interest.

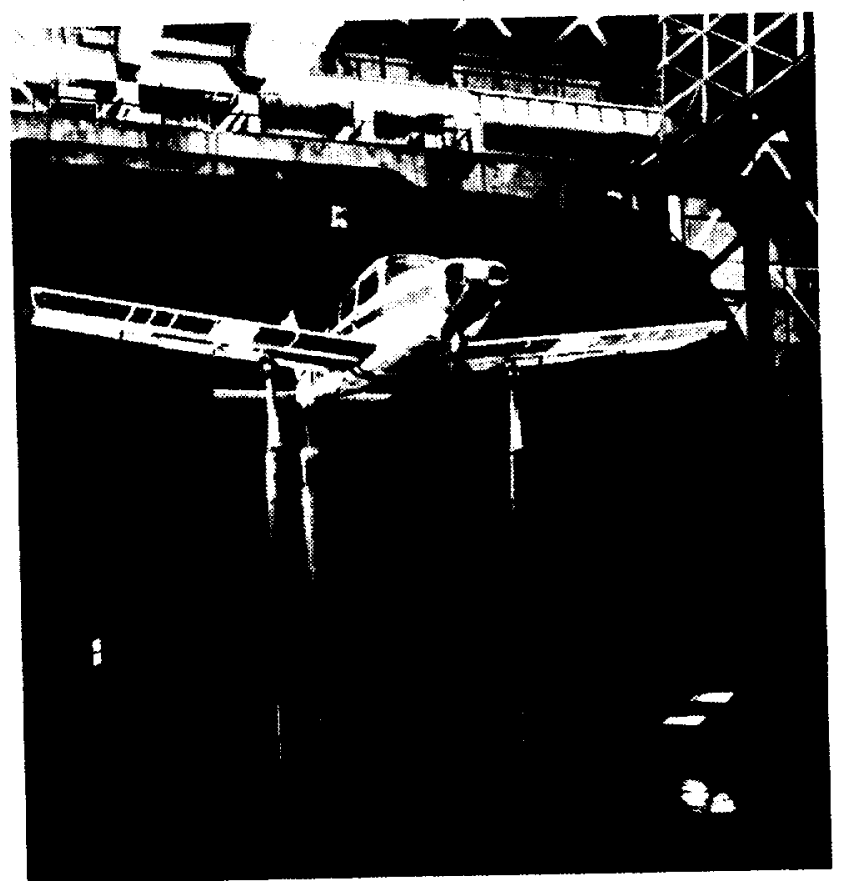

Fig. 3 Modified aircraft/wind-tunnel model mounted in NASA Ames $40 \times 80 \mathrm{ft}$ wind tunnel.

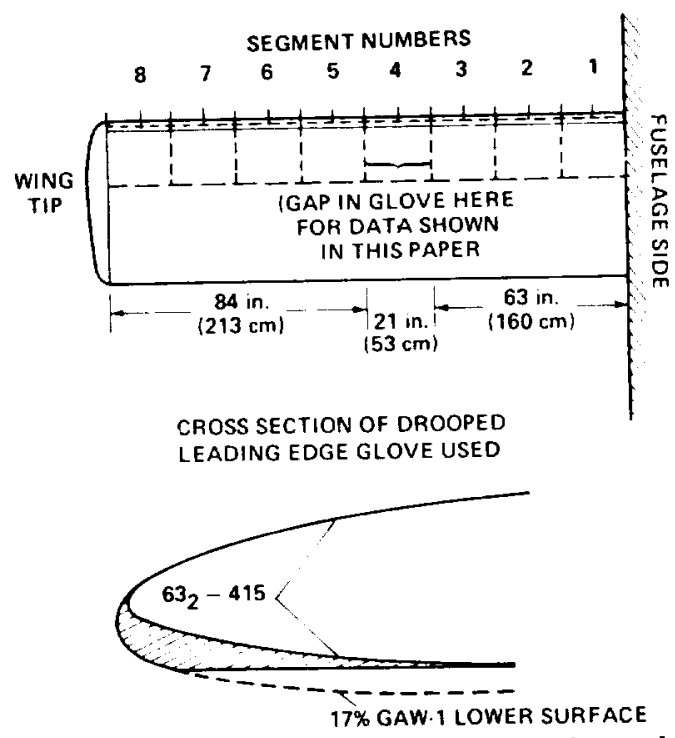

Fig. 4 Removable leading-edge glove, configuration and nomenclature.

The tests were run at an airspeed of about $77 \mathrm{mph}(124$ $\mathrm{kph).}$

\section{Results with Modified Leading Edge (Gap-in-Glove) and for Basic Aircraft-Clean Condition}

These tests with the full-scale airplane in the $40 \times 80 \mathrm{ft}$ wind tunnel confirmed the results obtained earlier with a model semispan wing in the $7 \times 10 \mathrm{ft}$ wind tunnel. ${ }^{6}$ That is, the most desirable position for the leading-edge discontinuity (based upon the shape of the lift curve, the rolling moments produced at stall, and the effectiveness of the ailerons) was a modification, 1/8 semispan in length (in this case, a gap-inthe-glove), located just inboard of the exposed midsemispan (position 4 in Fig. 4).

\section{Longitudinal Characteristics}

The lift curve for the modified configuration is compared with the basic aircraft characteristics in Fig. 6. (Note that 


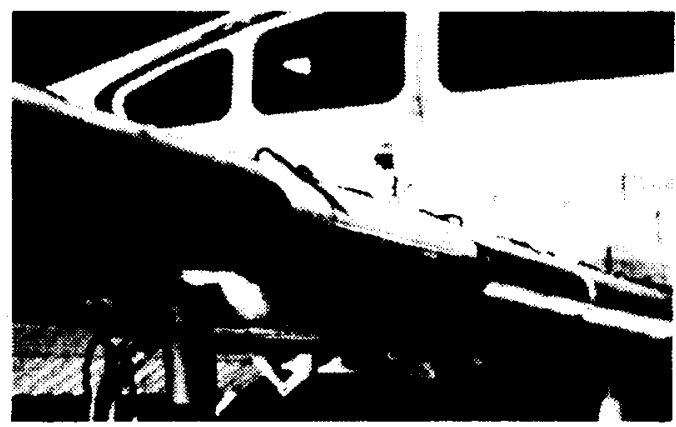

Fig. 5 Close-up of "gap-in-glove" modification.

these data are for the configuration with tail off, power off, and flaps up.) As can be seen, the modified configuration has a slightly higher $C_{L M A x}$. The significant effect, however, is that a high level of lift is maintained to a 32-34 deg angle of attack -instead of steadily decreasing at these high angles, as does the basic aircraft. From the tuft photographs, discussed below, it can be observed that the flow on the outer portion of the wings remains attached, with separation occurring in the vicinity of the midsemispan and inboard; the outboard areas then, which are the larger contributors to roll, presumably still have a positive lift curve slope, $C_{L_{\alpha}}$. It is hypothesized

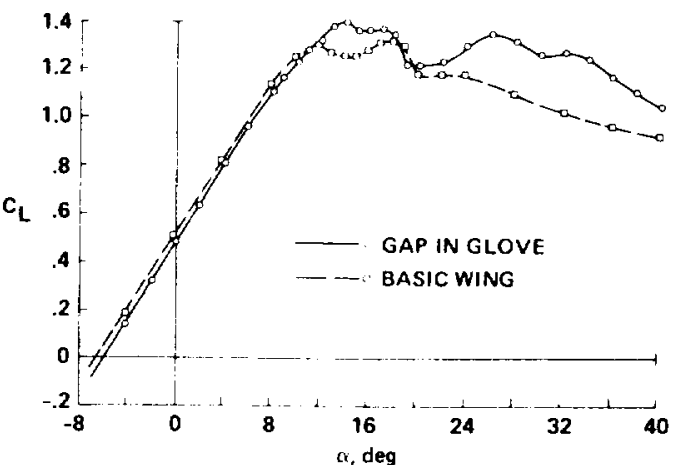

Fig. 6 Tail-off lift curve for modified aircraft, with data for basic aircraft superimposed.

that this characteristic implies improved roll damping in the poststall region. The extended negative slope of the basic configuration and the observed tip-flow separation, on the other hand, imply reduced roll damping-as it is known to occur in the classic poststall case.

\section{Flow Visualization}

The tuft photographs in Fig. 7 correspond to the lift curves shown in Fig. 6. They illustrate the flow structure over the
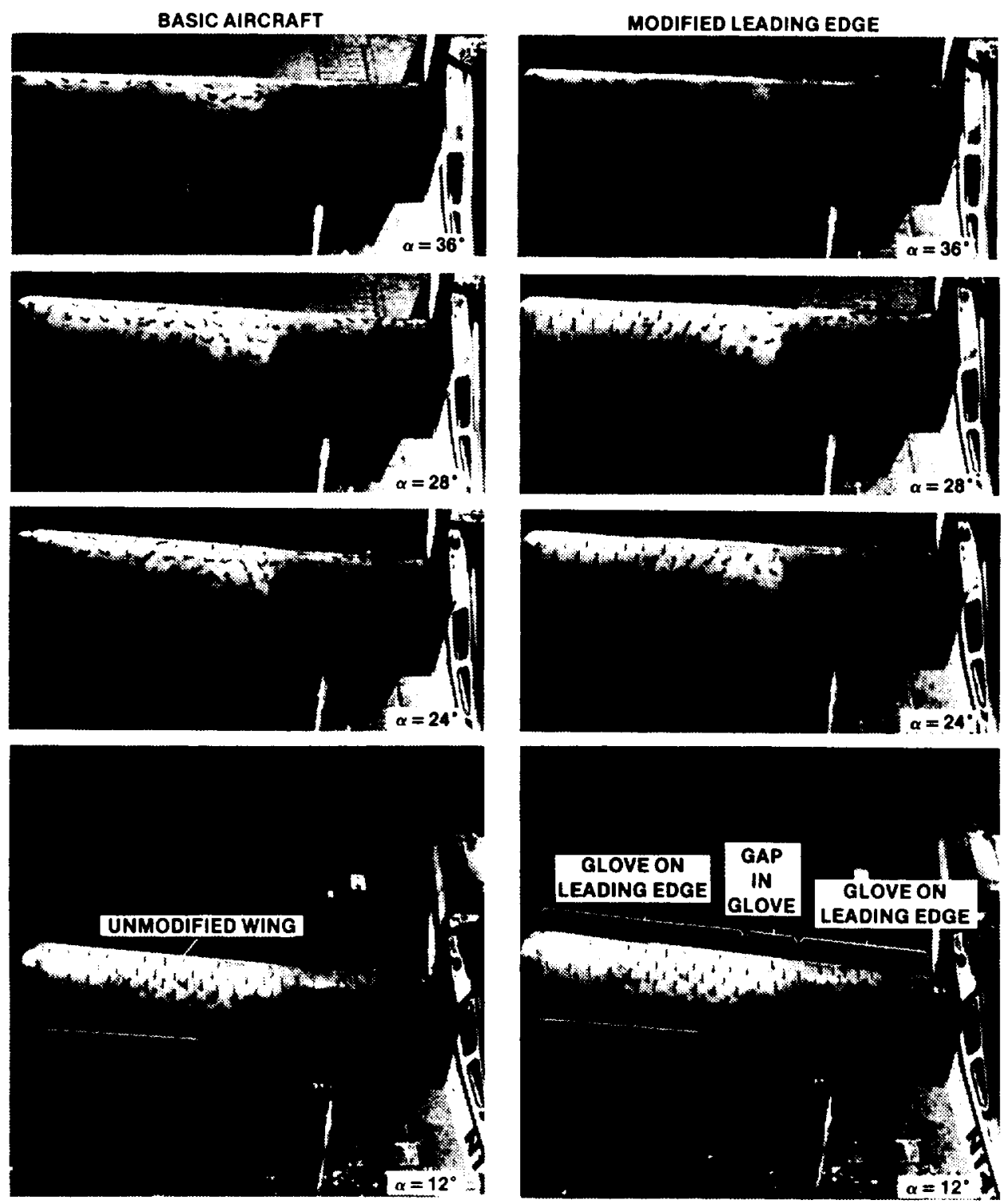

Fig. 7 Comparative fuft photographs of modified wings, $\alpha=12-36$ deg. 

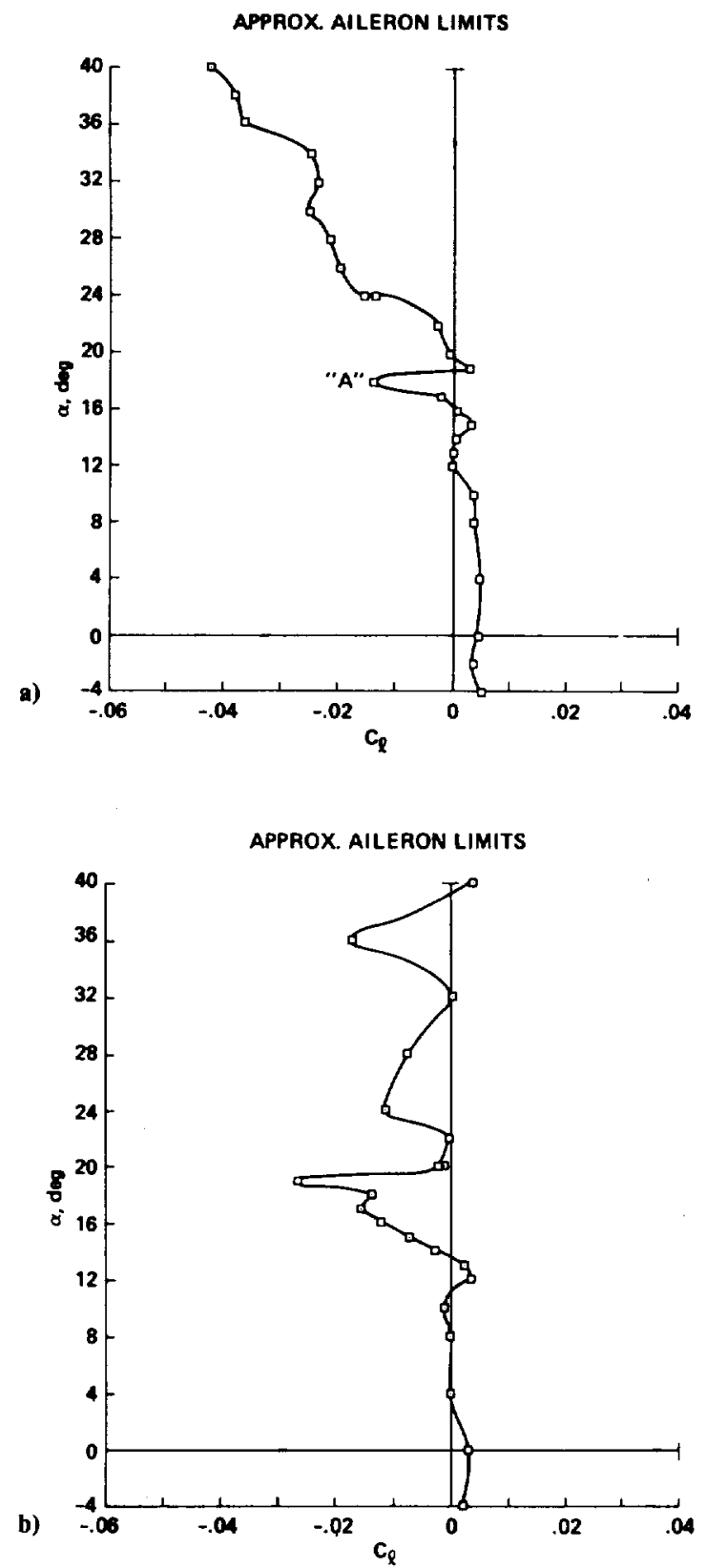

Fig. 8 Tall-off rolling-moment characteristics (power off, flaps up). a) Alrcraft with modified leading edge (gap-in-glove); b) basic aircraft.

wing for a range of angles of attack from immediately prestall to deep poststall. The photographs of the unmodified wing are on the left and those of the modified wing are on the right.

Starting with the bottom pair of photographs, the angle of attack $(\alpha)$ is $12 \mathrm{deg}$. As expected for this prestall angle, the flow is about the same on both the modified and unmodified wings, with a small amount of separation occurring at the trailing edge in the wing-root regions. The tuft patterns at $\alpha=16$ and $20 \mathrm{deg}$ (not shown) reveal little to distinguish between the two configurations. At $\alpha=24 \mathrm{deg}$ in the next pair of photographs, the favorable effect of the leading-edge modification is especially well illustrated, with the flow ahead of the aileron separated on the unmodified wing while it is still attached on the modified version; this combination remains through $\alpha=28 \mathrm{deg}$. In the final set of photographs at $\alpha=36$ $\mathrm{deg}$, the flow separation on the outboard portions of the modified wing, which was partial at $32 \mathrm{deg}$ (not shown), is complete. It is interesting to note that the tuft pattern for the modified wing at $\alpha=36 \mathrm{deg}$ is similar to that for the unmodified wing at $\alpha=24 \mathrm{deg}$.
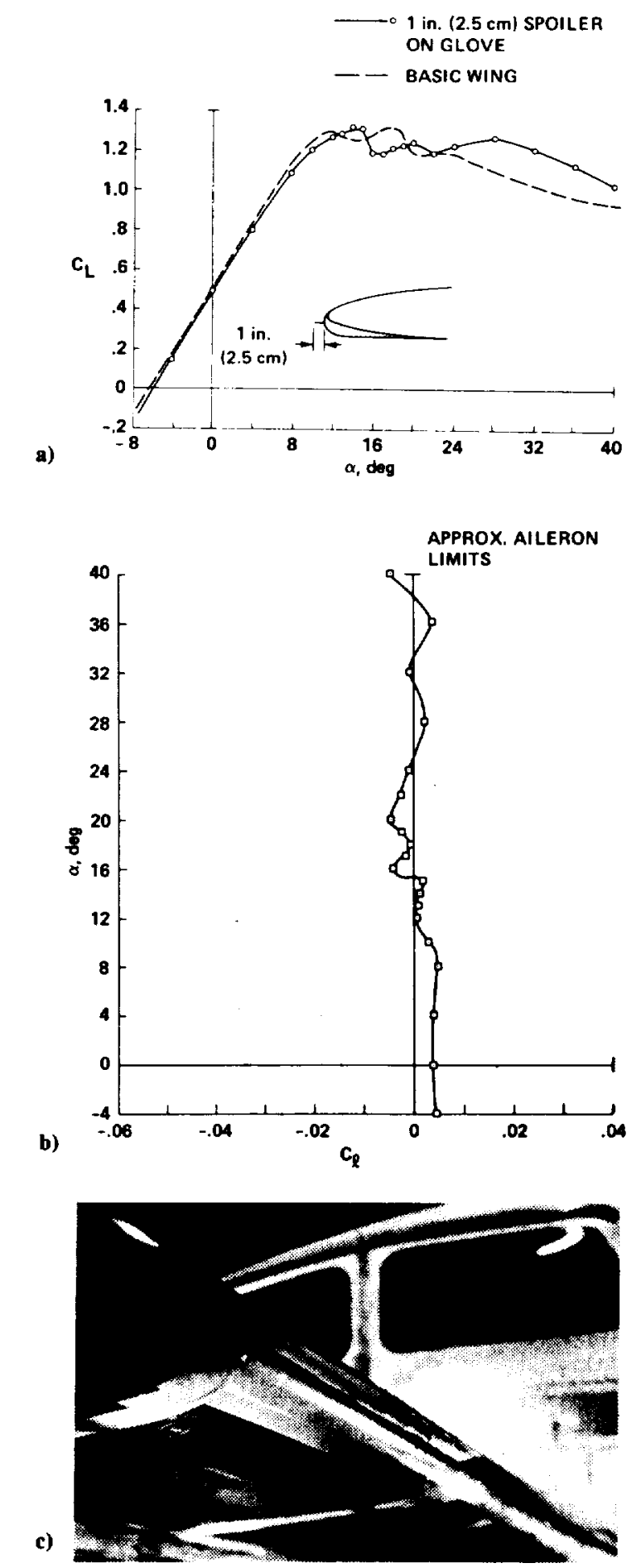

Fig. 9 Aircraft with full leading-edge glove-spoiler at position 4 (tail off, power off, flaps up). a) Lift characteristics; b) rolling moments; c) close-up of "spoiler-on-glove."

\section{Lateral Characteristics}

The rolling moment data for these two configurations, with neutral controls, and with approximate maximum roll-control limits (full aileron deflection, based upon data from aileron sweeps at selected angles of attack) are shown in Fig. 8. As would be expected from the tuft behavior, the rolling moments for the modified wing (in Fig. 8a) are fairly well behaved to an angle of attack of $32-34 \mathrm{deg}$, above which they start to depart. The excursion at $\alpha=18 \mathrm{deg}$ (point "A") is thought to be due to the leading-edge stall in the unprotected gap occurring on one wing first. The gradual divergence in the angle-of-attack range of $\alpha=20-34$ deg is probably due to 


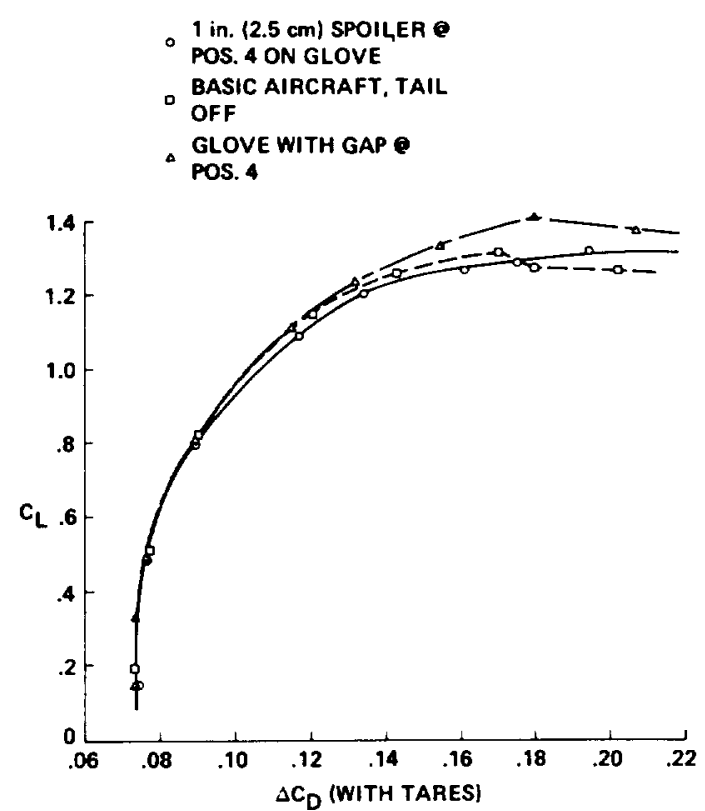

Fig. 10 Drag data for three configurations (tail off, power off, flaps up).

a)

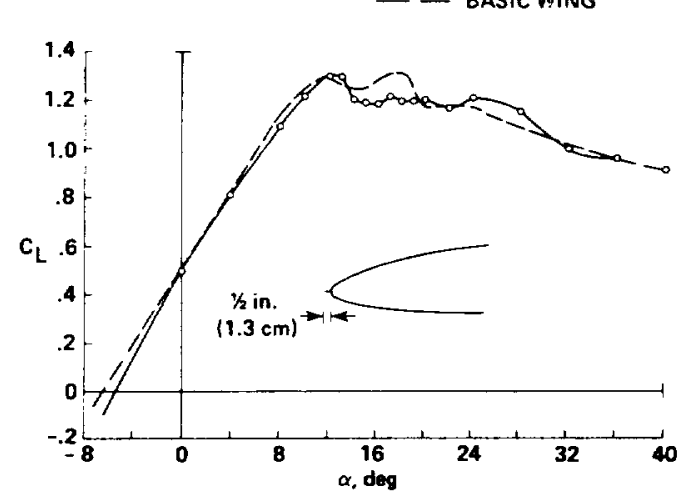

APPAOX, AILERON

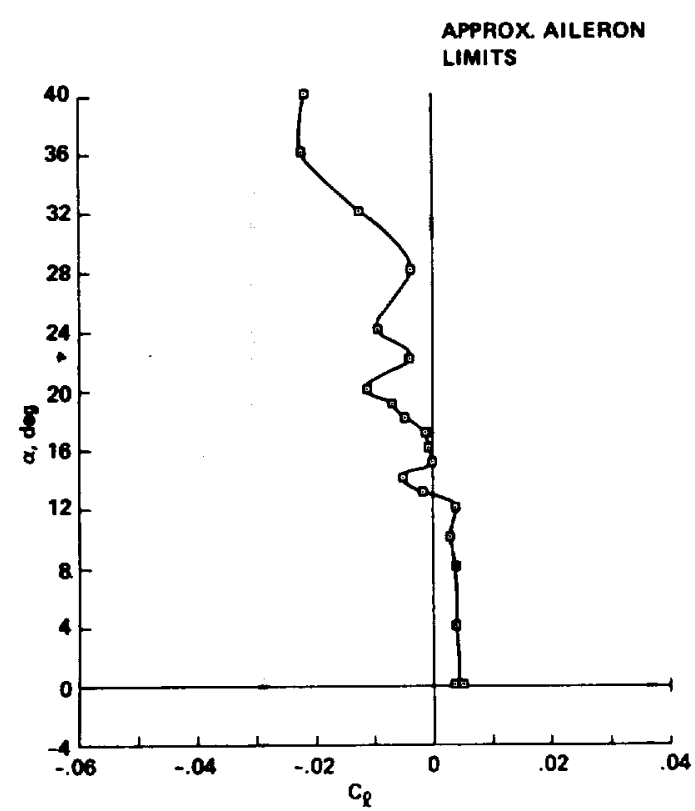

b)

Fig. 11 Basic aircraft with stall strip at position 4 (tail off, power off, flaps up). a) Lift characteristics; b) rolling moment.

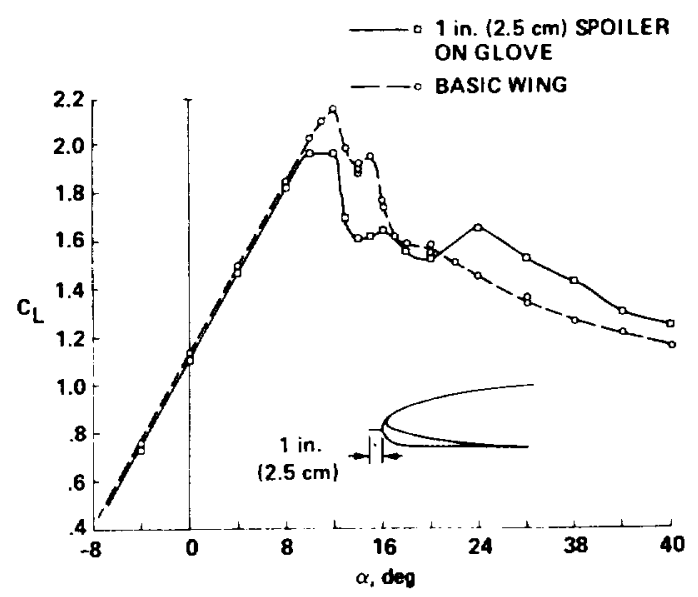

Fig. 12 Tail-off lift curves in landing approach condition (power on, flaps down), spoiler-on-glove configuration with basic aircraft superimposed.

APPROX. AILERON LIMITS

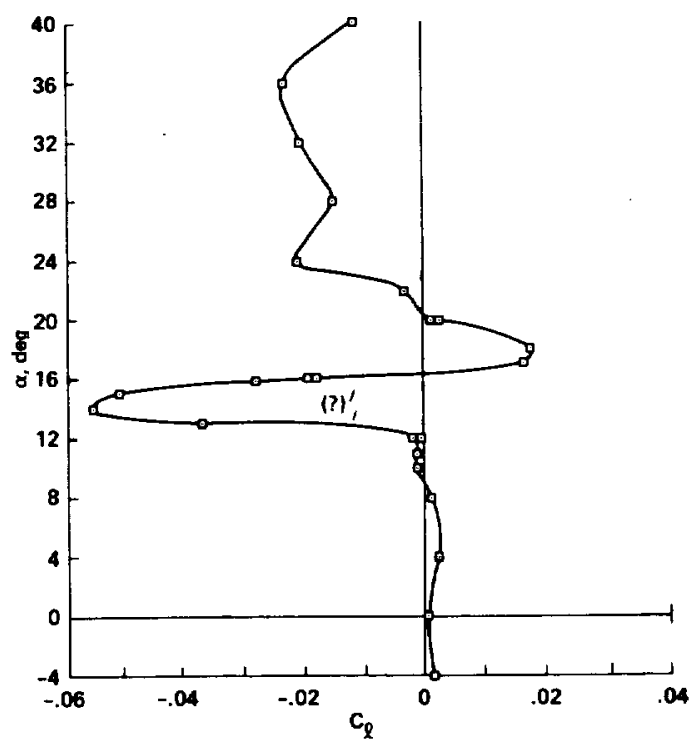

APPROX. AILERON LIMITS

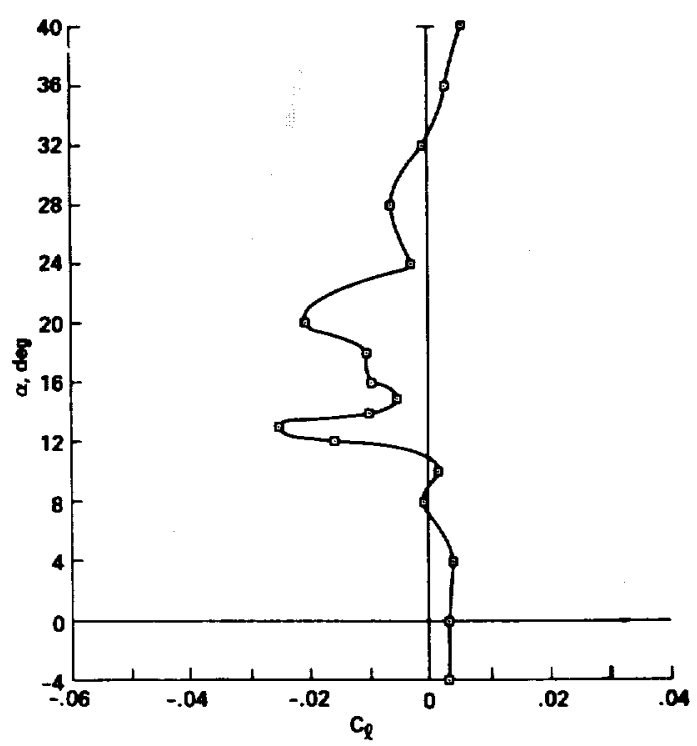

Fig. 13 Tail-off rolling-moment data, landing approach condition (power on, flaps down). a) Basic configuration; b) spoiler-on-glove configuration. 
asymmetric separation in the root, which was characteristic of this aircraft. For the unmodified wing (Fig. 8b) the divergence in rolling moment at $\alpha=12-20 \mathrm{deg}$ is more extreme. These large excursions are due to random asymmetric wing-flow separation which was observed in the tufts. In addition, the aileron effectiveness was substantially greater for the modified wing at the higher angles of attack, compared to that of the unmodified wing which dropped to very low values for angles of attack greater than $24-28 \mathrm{deg}$. The yawing moments for both versions (not shown) were relatively small. A cursory look at the contribution of the modification to dihedral effect $C_{b_{\beta}}$ and, to a lesser extent directional stability $C_{n \beta}$ (for the configurations tested with tail on), indicates that these parameters are enhanced somewhat at the higher angles of attack. The sensitivity of the poststall lateral characteristics of the modified aircraft to small yaw angles was investigated and found to be of little significance.

\section{Results with Two Other Types of Leading-Edge Modifications-Clean Condition}

To investigate other means for generating a strong leadingedge vortex flow, two additional leading-edge modifications were tested. Both incorporated a discontinuity at position 4 (Fig. 4) which was found to be the optimum location for the configuration with the gap in the leading-edge glove.

The first used the original leading-edge glove, fullspan, in combination with a $1 \mathrm{in}$. $(2.5 \mathrm{~cm})$ wide horizontally disposed leading-edge spoiler $1 / 8$ semispan long. The data for this variation, along with a sketch, are shown in Figs. $9 a$ and $9 b$. (Fig. $9 \mathrm{c}$ is a close-up photograph of the modification.) In this case, the maximum lift is about the same as for the basic wing. The shape of the lift curve is improved, however, maintaining a higher $C_{L}$ level at higher angles of attack. Of greatest significance is the improvement in rolling moment which shows no appreciable divergence up to $40 \mathrm{deg}$ angle of attack. This is probably due to strong vortices being shed symmetrically, on both wings, by the leading-edge spoilers.

The drag data for the two modified configurations discussed thus far, along with that for the basic configuration, are shown in Fig. 10. There was no appreciable drag penalty for either of the modifications in the 0.2-0.8 $C_{L}$ range where drag is most significant. As would be expected, the leadingedge spoiler produced a measurable drag increment at the higher $C_{L}$, but this would be felt primarily in the landing approach and could be regarded as beneficial. No attempt was made to optimize the vertical location and orientation of the spoiler, which could serve to bias this $C_{L}$ range to higher or lower values.

Another leading-edge modification investigated resembled the conventional stall control treatment used on current light aircraft. It employed the basic wing (with no leading-edge glove), and consisted of a $0.5 \mathrm{in} .(1.3 \mathrm{~cm})$ wide "stall strip" at the same position 4 (Fig. 4). The resulting lift curve (Fig. 11a) shows little significant improvement over that of the basic wing. The rolling moments (Fig. 11b) stayed within the limits of aileron control power to high angles of attack (for this power off, flaps up condition, at least-larger excursions would possibly occur in the landing approach condition). At higher angles of attack, however, the lateral control power available became undesirably small; this characteristic was typical of all configurations with the leading-edge glove off.

\section{Characteristics of the Aircraft with Modified Leading Edge in the Landing Approach Condition}

Data are shown in the concluding figures to compare the effectiveness of the $1 \mathrm{in}$. $(2.5 \mathrm{~cm})$ leading-edge spoiler-on-theglove modification described earlier for the critical fullflapped, power on, landing approach condition $\left(\delta_{F}=33 \mathrm{deg}\right.$, $1800 \mathrm{rpm}$ ) with the corresponding data for the basic aircraft. In Fig. 12, the lift curves for the two configurations are shown superimposed. The basic aircraft has a higher and slightly sharper maximum lift peak, but the lift falls to lower values at higher angles of attack.

The modified configuration has a truncated lift peak with a second peak at $\alpha=24 \mathrm{deg}$. The negative slope for $\alpha>24 \mathrm{deg}$ was observed to be due to rapidly progressing separation in the flapped center sections. The outer portions of the wings stayed attached at the high angles of attack, implying that the improved roll damping discussed earlier could result.

The rolling moment data are shown in Fig. 13. The basic aircraft (Fig. 13a) has a very large roll divergence at $\alpha=14 \mathrm{deg}$ with greatly diminished aileron effectiveness at the higher angles $(\alpha>20-24 \mathrm{deg})$. The data for the modified aircraft (Fig. $13 \mathrm{~b})$ on the other hand, show much less serious roll divergence along with more adequate aileron effectiveness beyond stall, implying that the pilot would have an easier time maintaining control in this critical condition.

These data for the spoiler-on-glove configuration are deemed consistent and repeatable, since the sharp leading edge of the spoiler assures a precise separation point. It was found, however, for the gap-in-glove configuration in the landing approach condition (the results from one test of which are shown in Ref. 7) that high rolling moments were occasionally obtained. This was probably due to separation occurring earlier at angle of attack in one gap than the other. Based upon results from the configurations tested, the leading-edge spoiler-on-glove is considered to be the more practical modification since it consistently assures a more precise symmetrical separation at a particular angle of attack and, at the same time, produces no significant drag penalty in the normal flight regime. It is also more universally applicable to a variety of airfoils and entails less structural modification to the wing.

The model was also tested with a full leading-edge glove having no discontinuities. As expected, this configuration (data not shown), with no fixed spanwise position for the onset of separation to occur, exhibited extreme roll-off tendencies in the landing approach condition. (This result is consistent with the poor spin characteristics observed for a similar configuration in Ref. 5).

\section{Conclusion}

A study has been made of several wing leading-edge modifications that change the stall pattern so that the onset of separation tends to occur at the midsemispan leading edge. Vortices shed at this position reduce the tendency for flow separation to occur on the inboard and outboard portions of the wing, so that the flow separation pattern is stabilized, maintaining high lift to large angles of attack and causing the attached portions of the wing to behave similarly to lowaspect-ratio surfaces. The resulting aerodynamic characteristics of the airplane are improved in several of the important aspects affecting spin tendencies. For example, while $C_{L_{\text {MAX }}}$ is about the same as for the unmodified wing, the shape of the top of the lift curve for the modified wing is flatter so that it maintains a higher level of lift to approximately 32-34 deg angle of attack. In addition, flow visualization studies show that the flow over the outboard portion of the wing remains attached to much higher angles of attack than for the unmodified case, indicating that favorable effects on poststall roll damping would be expected. The poststall excursions of the rolling moment are decreased, so that they stay within acceptable levels to angles of attack of 28-32 deg. Yawing moments also are within satisfactory limits. Finally, the effectiveness of the ailerons is maintained to much higher angles of attack with the modified configuration.

\section{References}

'Anderson, S.B., "Historical Overview of Stall/Spin Characteristics of General Aviation Aircraft," Journal of Aircraft, Vol. 16, July 1979. (See this paper for further background references). 
${ }^{2}$ DiCarlo, D.J. and Johnson, J.L., Jr., "Exploratory Study of the Influence of Wing Leading-Edge Modifications on the Spin Characteristics of a Low-Wing General Aviation Airplane," Paper 79-1837 presented at AlAA Aircraft Systems and Technology Meeting, New York, Aug. 20-22, 1979.

3 "Exploratory Study of the Effects of Wing Leading-Edge Modifications on the Stall/Spin Behavior of a Light General Aviation Airplane Configuration," NASA TP-1589, 1979.

"Winkleman, A.E., Barlow, J.B., Saini, J.K., Anderson, J.D., Jr., and Jones, E., "The Effects of Leading-Edge Modifications on the Poststall Characteristics of Wings," Paper 80-0199 presented at AIAA Aerospace Sciences Meeting, Pasadena, Calif., Jan. 14-16, 1980.
sWeener, E.F., "Stalled and Partially Stalled High Aspect Ratio Straight Wings," Ph.D. Dissertation, Dept. of Aerospace Engineering, University of Michigan, Ann Arbor, 1975.

${ }^{6}$ Kroeger, R.A. and Feistel, T.W., "Reduction of Stall-Spin Entry Tendencies Through Wing Aerodynamic Design," Paper 76-0481 presented at SAE Business Aircraft Meeting, Wichita, Kans. April 6$9,1976$.

${ }^{7}$ Feistel, T.W., Anderson, S.B., and Kroeger, R.A., "A Method for Localizing Wing Flow Separation at Stall to Alleviate Spin Entry Tendencies," Paper 78-1476 presented at AIAA Aircraft Systems and Technology Conference, Los Angeles, Calif., Aug. 21-23, 1978. 